\title{
Probability disclosures are not enough: Reducing loot box reward complexity as a part of ethical video game design
}

\author{
Leon Y. Xiao ${ }^{1,2^{*}}$, Philip Newall ${ }^{3,4}$
}

Citation: Xiao, L. Y., Newall, P. (2022). Probability disclosures are not enough: Reducing loot box reward complexity as a part of ethical video game design. Journal of Gambling Issues.

Editor-in-Chief: Nigel Turner, $\mathrm{PhD}$

Received: 05/07/2021 Accepted: 28/03/2022

Published: 13/05/2022

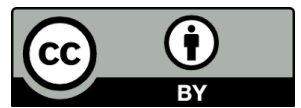

Copyright: @2022 Xiao, L. Y., Newall, P. Licensee CDS Press, Toronto, Canada. This article is an open access article distributed under the terms and conditions of the Creative

Commons Attribution (CC BY) license (http://creativecommons. org/licenses/by/4.0/)
${ }^{1}$ Center for Digital Play, IT University of Copenhagen, Denmark; School of Law, Queen Mary University of London, UK; The Honourable Society of Lincoln's Inn, UK; The City Law School, City, University of London, UK.

${ }^{2}$ ORCiD: 0000-0003-0709-0777

${ }^{3}$ University of Bristol, UK; CQUniversity, Australia.

${ }^{4}$ ORCiD: 0000-0002-1660-9254

*Corresponding author: Leon Y. Xiao: leon.xiao.y@gmail.com

Abstract: Loot boxes are virtual products in video games that provide randomized rewards, and accordingly share structural similarities with gambling. Policymakers around the world are presently considering how best to regulate loot boxes. Current loot box consumer protection measures, such as requiring probability disclosures, have been inspired by similar harm reduction approaches in gambling. However, unlike in many gambling games, most loot boxes' reward structures are arguably too complex for consumers to be meaningfully protected by probability disclosures alone. But promisingly, loot boxes can readily be redesigned to be more ethical because they are digital products. Based on behavioural science principles, this article proposes four reductions to loot box reward complexity. The decisionmaking environment can be simplified by capping (i) the maximum number of loot boxes per game and (ii) the maximum number of potential rewards per loot box, and by (iii) equalizing winning probabilities across rewards. Additionally, (iv) companies can implement "exhaustible" loot boxes that provide the player with every potential reward after a predetermined amount of money has been spent, thereby effectively instituting a maximum spending limit. These ethical game design proposals can credibly reduce financial harms from loot boxes while both maintaining consumer freedom and preserving companies' commercial interests.

Keywords: Loot Boxes; Gambling; Video Gaming Regulations; Consumer Protection Law; Ethical Game Design; Video Games; Gaming Law; Microtransactions. 


\section{Introduction}

Paid loot boxes are virtual items in video games that players can purchase with real-world money to obtain randomized rewards possessing value in the game's virtual economy, and potentially also in the real-world economy (Nielsen \& Grabarczyk, 2019; Xiao, Henderson, Nielsen, et al., 2021). Loot boxes have become an important revenue stream for the video game industry, which is now larger than the music and movie industries combined in the UK (BBC, 2019). The loot boxes in one single game was able to generate more than US $\$ 500,000$ in revenue in one day in one country alone (Zendle, Petrovskaya, et al., 2020). Loot boxes are arguably psychologically and structurally similar to gambling (Drummond \& Sauer, 2018; Xiao, 2021a, 2022), and loot box engagement has been found to be positively correlated with disordered gambling (Zendle \& Cairns, 2018; Brooks \& Clark, 2019; Kristiansen \& Severin, 2019; Li et al., 2019; Macey \& Hamari, 2019; Zendle, 2019a, 2019b; Zendle \& Cairns, 2019; Zendle, Meyer, et al., 2019; Zendle, Cairns, et al., 2019; Drummond et al., 2020; von Meduna et al., 2020; Wardle \& Zendle, 2021; Close et al., 2021; Garea et al., 2021; Hall et al., 2021; Rockloff et al., 2021). Loot boxes are widely implemented in video games internationally, and are therefore broadly accessible to a significant proportion of the world's population, including more vulnerable consumers, such as children, in both developed and developing countries (Xiao, Henderson, Yang, \& Newall, 2021; Zendle, Meyer, et al., 2020).

Loot boxes represent a relatively new innovation in video games, and many countries are still deciding how best to regulate them (Derrington et al., 2021). Banning the sale of loot boxes, as effectively done in Belgium (Belgian Gaming Commission, 2018), may overly restrict both the players' enjoyment of games and the companies' commercial interests. Some companies were forced to remove certain games from the Belgian market because the compulsory removal of loot boxes from those games meant that they were no longer commercially viable (Nintendo, 2019). In contrast, taking no regulatory action, as is the position in the UK (UK Gambling Commission, 2017), potentially exposes vulnerable consumers to significant financial harms (Cerulli-Harms et al., 2020; Xiao, 2021b). A diverse range of developed and developing countries around the world are considering how best to regulate loot boxes, including Spain (O'Boyle, 2021), Australia (Batchelor, 2020) and Brazil (Dealessandri, 2021).

The People's Republic of China (PRC) has adopted a unique consumer protection approach to loot box regulation by legally requiring video game companies to disclose the probabilities of obtaining potential rewards (Xiao, Henderson, Yang, \& Newall, 2021; Xiao \& Henderson, 2019). This non-restrictive approach mimics information-based interventions for reducing gambling-related harms (Livingstone et al., 2019; Newall et al., 2020), and seemingly balances harm prevention while 
preserving the consumer's freedom to choose (Xiao, Henderson, Yang, \& Newall, 2021). This disclosure-based approach has been recommended as a loot box consumer protection approach in other countries (King \& Delfabbro, 2019b; McCaffrey, 2019). Indeed, this cautious and balanced approach is also arguably more appropriate than either the prohibitive Belgian approach or the laissez-faire UK approach, because although research has established that loot boxes are potentially harmful for the variety of reasons discussed above, they have yet to be associated with either short- or long-term harms. Therefore, any precautionary policy imposed at this early stage should reflect this currently limited state of scientific understanding and seek to be attentive by providing a degree of protection-while also remaining reasonably skeptical, so as to not be unnecessarily restrictive.

\section{Loot Box Probabilities Are Less Intuitive Than Many Gambling Probabilities}

At present, probability disclosures are arguably even more important for loot boxes than they are in certain traditional gambling contexts, because loot boxes often involve unintuitive probabilities. Many gambling formats allow gamblers to at least roughly estimate their odds of winning. For example, a European roulette wheel has 37 identically sized slots the ball can fall into, yielding a probability of winning of approximately $2.7 \%$ for single-number bets. But there is no similarly intuitive way for video gamers to infer the probability of winning a specific loot box reward simply by observing the product, unless a probability disclosure is provided. This is further exacerbated by the fact that many loot boxes involve astronomically low chances to win certain rewards, such as $0.0008 \%$ (Xiao, Henderson, \& Newall, 2021). Indeed, other gambling activities that involve ambiguous probability structures, such as some lotteries and scratch cards, often provide supplemental information to assist customers in understanding their odds of winning - although prior research has noted that many such disclosures may not have been provided in an effective manner (Newall et al., 2020; Walker et al., 2019).

Loot boxes that mimic casino games provide a clear demonstration of the unintuitive nature of loot box probabilities when compared to the traditional games that they resemble. For example, the loot box in Slots (Golden HoYeah) - Casino Slots (Figure 1) is represented as a dice-rolling game that is somewhat similar to the casino game of craps. A jackpot reward can be won by rolling three sixes, and lesser rewards are won for rolling lower numbers, such as three ones. Even though the dice appear symmetric, they are in fact loaded by design to ensure that valuable rewards are less likely to be paid out. The probability disclosure shows that the probability of rolling three ones is $8.5 \%$, while it is $1.05 \%$ for three sixes. The player would be mistaken if they assumed the probabilities of rolling three sixes and three ones are equal, which would be true in a real-life casino-both would be approximately $0.46 \%$. Complex and arguably deceptive reward 
payoff schedules, such as this, illustrate the pressing need to implement consumer protection measures like probability disclosures for loot boxes.

\section{Probability Disclosures Reveal the Complexity of Loot Box Design}

Behavioural science research, however, shows that disclosures can only be understood by most consumers in relatively simple decision-making environments (Loewenstein et al., 2014; Page, 2021), and that they are not always a risk-free method of consumer protection (Bar-Gill, 2021). When decision-making environments are complex, consumers are likely to default to using a range of simplifying heuristics that fail to correctly account for all relevant data (Tversky \& Kahneman, 1974). And unlike casino games, such as roulette, loot boxes are digital products, so there are no physical limits on their potential complexity (Ballou et al., 2020).

A survey of the PRC's 100 highest-grossing iPhone games' probability disclosures revealed the high levels of loot box complexity currently being implemented: games contained up to 433 different types of loot boxes, some of which contained up to 80 potential rewards (Xiao, Henderson, Yang, \& Newall, 2021). Some loot boxes in Western countries have been known to contain more than 1000 different potential rewards each (Ballou et al., 2020). Moreover, 65.9\% of games with loot boxes in the PRC disclosed implementing a mechanic known as a "pity-timer" by the video gaming community, which causes the probability of winning a rare reward to increase as the player purchases more loot boxes without winning one (Ballou et al., 2020; Whitson \& French, 2021; Xiao, Henderson, Yang, \& Newall, 2021). Figure 2 shows an example from a loot box probability disclosure published in the UK, illustrating how the probability of winning a valuable "Mario (Happi)" reward increased from $1 \%$ to $1.11 \%$ after a few purchases were made. This host of complex and changing statistical information underlying current loot box design suggests that probability disclosures are unlikely to effectively influence video gamers' purchasing behaviour (Weiss-Cohen et al., 2018).

\section{Probability Disclosures Are Not Effective at Reducing Spending in Practice}

A survey of video gamers in the PRC $(N=879)$ found that while $84.6 \%$ of loot box purchasers reported they had seen the probability disclosures, only $16.4 \%$ reported spending less money on loot boxes as a consequence of seeing probability disclosures (Xiao 2021). These numbers suggest that even if $100 \%$ of loot box purchasers saw probability disclosures, only about $20 \%$ of them would buy fewer loot boxes as a result. Stronger interventions will therefore likely be necessary to more effectively reduce potential loot box spending harms. The study by Xiao, Fraser, \& Newall (2021) was a cross-sectional survey and not longitudinal, therefore it was not possible to compare players' spending before and after being exposed to probability disclosures. However, it is worth considering how the small minority of players who reported spending less money after seeing 
probability disclosures potentially differ from other players in the sample. Probability disclosures might have varying levels of efficacy at reducing spending depending on how committed the player is to purchasing loot boxes: probability disclosures might work better on less committed players than on higher-spending players.

The results of a reanalysis of the data from Xiao, Fraser, \& Newall $(2021)^{\text {note }}$, applying the original exclusion criteria, are consistent with this proposition: among all players who reported seeing probability disclosures $(n=653)$ and therefore must have had the opportunity to choose to buy loot boxes (even though some of them decided not to do so), those who reported spending less money after seeing disclosures $(n=156 ; 23.9 \%)$ indeed spent significantly less money on loot boxes, $t(651)=2.1, p=.02$. It cannot be conclusively determined why such players spent less money than others due to the cross-sectional nature of the data, because mere exposure to probability disclosures is not the only potential explanation. Alternative interpretations include, for example, that players who would report spending less money on loot boxes after seeing probability disclosures are more risk-averse than other players, such that they would have spent less money on loot boxes regardless of whether they saw probability disclosures. However, the results do suggest that probability disclosures have not effectively targeted the highest-spending players (which represent the type of player that is arguably most in need of consumer protection) given that those players who report spending less money after seeing the disclosures tend to already be lower-spending players.

It is plausible that probability disclosures more effectively reduce spending by lower-spending players who are only minimally engaged with loot boxes and are therefore more easily discouraged to buy them, and that they do little to dissuade more committed and higher-spending purchasers. Therefore, probability disclosures might be unhelpful at reducing extreme harms and ineffective at targeting the players who are more likely to be problem gamblers and most in need of consumer protection (Close et al., 2021). Observational data examining the effects of implementing probability disclosures before and after the event would shed more light on this issue.

\section{Video Game Companies Always "Win" and Do Not Need to Preserve the "House Edge"}

Loot box winning probabilities are less intuitive than they are in many gambling contexts, but loot boxes also offer greater potential for implementing consumer protection measures. This is because the relationship between a video game player and a game company is different from that between a gambler and a gambling operator. Gambling is a zerosum game: any money lost by the gambler is gained or "won" by the operator, and vice versa. The situation is fundamentally different with loot boxes: if the video gamer "loses" from a loot box by not getting a good reward, the game company makes money; if the video gamer "wins" by 
getting a valuable reward, the game company still makes money anyway (albeit potentially less than if the gamer had "lost" and then decided to purchase additional loot boxes). The game company makes money and "wins" on every transaction regardless of what the loot box contains.

This distinction means that video game companies can afford to increase the video gamers' odds of winning for loot boxes and still make money, whereas a casino usually cannot as it would then lose the house edge (e.g., approximately $2.7 \%$ in European roulette) and start losing money as more bets are made. There is no equivalent house edge that a video game company needs to preserve with loot boxes: each additional loot box sale remains an overall revenue gain, regardless of the odds of winning; the company cannot lose money from a loot box being purchased.

While a profit-maximizing video game company may prefer to set lower probabilities for winning valuable rewards, this is a choice and not an indispensable feature. It is not strictly necessary for video game companies to sell an inherently "unfair" product, unlike for gambling providers. Increasing the video gamer's odds of winning might make it more difficult for the video game company to recoup its costs of designing and producing the in-game content, but each additional loot box transaction will still positively contribute to this. Doing so might also cause more players to decide to purchase loot boxes, because what used to be the rarer rewards are now easier to obtain and more affordable, thus leading to an overall revenue increase. Indeed, the assumption that the existing designs of commercial loot boxes effectively maximize profitability has been questioned (see Chen et al., 2020).

\section{Ethically Designed Loot Boxes}

A key consumer protection mechanism available for loot boxes (but not in traditional gambling) is therefore to make loot boxes "fairer" by, for example, giving video gamers a higher probability of winning valuable rewards, and reducing the complexity of loot box design so that players can more easily understand what they are buying. Accordingly, the following four consumer protection measures for ethically designed loot boxes are proposed.

\section{Capping the Maximum Number of Loot Boxes per Game}

Modern video games can have over 400 different types of loot boxes within a single game (Xiao, Henderson, Yang, \& Newall, 2021). A game with many loot boxes, each of which potentially has unintuitive winning probabilities, limits the ability of probability disclosures to meaningfully educate video gamers (Loewenstein et al., 2014). In fact, if probability disclosures are the only consumer protection measure, then a strategic game company may intentionally increase the number and variety of loot boxes in their games in order to weaken the effectiveness of this consumer protection measure (Persson, 2018). As with other proposed measures below, a maximum limit on the number of loot boxes that may be 
implemented in a single game would allow video game companies to continue to monetize their games in this way, while reducing the complexity of reward structures so that players can better understand them.

\section{Capping the Maximum Number of Potential Rewards per Loot Box.}

Currently, one type of loot boxes can contain over 80 individual rewards (Xiao, Henderson, Yang, \& Newall, 2021), creating a further complexity hurdle for probability disclosures. A large number of rewards makes any calculation or estimation of the expected value of each loot box more difficult, and allows the game company to continue selling loot boxes with alluring, rare and valuable rewards despite only providing less valuable rewards the vast majority of the time. Further limiting the number of potential rewards per loot box type to a more manageable number, such as 25 , will therefore likely be necessary for any disclosure to be effective (Weiss-Cohen et al., 2018).

\section{Equalizing Probabilities Across Rewards}

When faced with multiple possibilities, decision-makers have a bias toward believing that each probability is equally likely (Fischhoff \& Bruin, 1999). Loot boxes with an equal probability of obtaining each reward would in fact make this decision-making strategy "ecologically rational" (Todd \& Gigerenzer, 2012). This could make loot boxes simple enough that even probability disclosures may not be necessary. Furthermore, forcing the probability of winning each reward to be equal would prevent game companies from adopting a range of complexity-increasing features to their loot boxes, such as pity-timers (Xiao, Henderson, Yang, \& Newall, 2021). Rarer rewards (that are cosmetically more attractive or stronger in competitive settings) were created so that at least some players would be motivated to "chase" these by buying more loot boxes to gain social prestige or competitive advantages, particularly in multiplayer games (Larche et al., 2021; Nicklin et al., 2021). However, with equal probability loot boxes, players would be able to make purchasing decisions in a more straightforward manner, and would not have to learn, remember and process "a wide range of probabilities," as was recently admitted to have been implemented by Electronic Arts (2019) in their FIFA games' loot boxes. Equalizing probabilities would also mean that the odds of getting those more cosmetically attractive or competitively stronger rewards (i.e., what used to be the rarer rewards) are increased such that players are more likely to get them.

\section{Implementing "Exhaustible" Loot Boxes}

Loot boxes can be made "exhaustible" by guaranteeing that a player cannot obtain duplicate rewards. Players may continue to open loot boxes despite obtaining duplicate low value rewards in order to chase the more valuable rewards. The potential to get duplicate rewards means that an "unlucky" video gamer could have to buy more than 100 loot boxes from a 
loot box containing 100 potential rewards in order to get their desired higher value reward (King \& Delfabbro, 2019b). As an analogy, imagine a gambler trying to pick out the ace of spades from a deck of 52 cards: after each pick, their card is returned to the deck, which is shuffled before the next pick. It could easily take well over 52 picks before the gambler obtains the ace of spades. Removing each card from the deck after it has been picked once is equivalent to creating an "exhaustible" loot box without duplicate rewards. Players have expressed frustration when they realized that they had purchased useless or duplicate in-game products (Petrovskaya \& Zendle, 2021). This possibility would be removed if the reward obtained is guaranteed to be one that the player does not already have.

Indeed, obtaining useless duplicate rewards from loot boxes has been recognized by video game companies, such as Blizzard Entertainment in the context of Hearthstone card packs, as leading to "a bad player experience" that causes players to be "very unhappy," which is why Blizzard Entertainment took steps six years after Hearthstone's initial release to change the game's loot box prize distribution system and avoid providing duplicate rewards (in certain situations) to improve the user experience and make the game more affordable (Kilkku, 2020). Exhaustible loot boxes also allow the player to effectively calculate the maximum number of loot boxes they may need to purchase in order to obtain a particular reward, therefore effectively creating a maximum spending limit for any individual reward (Drummond et al., 2019; King \& Delfabbro, 2019a).

\section{Conclusion}

Information-based interventions to reduce harm have been recommended both for gambling (Livingstone et al., 2019; Newall et al., 2020) and for loot boxes (King \& Delfabbro, 2019b; McCaffrey, 2019). The need to address the nonintuitive probabilities of winning loot box rewards is one reason in favour of providing loot box probability disclosures. However, the actual complexity of current loot boxes, with respect to the number of loot box types per game; the number of potential rewards per loot box type; and the potential for the winning probabilities to change over time, diminishes the potential effectiveness of the disclosure-based approach (Loewenstein et al., 2014). Indeed, empirical results suggest that optimal loot box probability disclosures might only help one in five video gamers to consequently spend less money (Xiao, Fraser, \& Newall, 2021).

Simply improving how the probabilistic information is presented might enhance players' comprehension of the disclosures. For example, probabilities could be stated as frequencies like " 1 in every 200 loot boxes contains the rare reward", rather than percentage probabilities like "rare reward: 0.5\%" (Gigerenzer \& Hoffrage, 1995), or visual graphical aides could be included (Garcia-Retamero \& Cokely, 2017; Walker et al., 2019). However, subtle changes might only bring minor benefits, and more can be done to immediately enhance transparency and fairness to provide better consumer protection. Promisingly, loot boxes differ from traditional 
gambling in that video game companies do not need to maintain the house edge that casinos require to make money and so there are no inherent upper limits on the players' odds of winning valuable loot box rewards. A potentially more successful consumer protection measure is therefore to encourage or require (through law or self-regulation) ethically designed loot boxes - specifically, fewer and exhaustible loot boxes per game, with each loot box containing fewer potential rewards with equal probabilities.

Ethically designed loot boxes may be potentially less profitable for the industry in the short run, but they are fairer to the players. In any case, when compared to banning loot boxes outright as gambling, which was recently effectively done in Belgium (Belgian Gaming Commission, 2018), an ethical game design approach has the key commercial advantage of still allowing game companies this revenue stream. This is why in the face of regulatory scrutiny and concerns about looming overregulation, game companies should prefer to adopt this approach (and, perhaps, accept some minor losses in the short run) to appease both players and regulators, rather than to continue to act irresponsibly and risk more severe sanctions and more significant losses in the long run (Xiao, 2021b).

Many companies depend on loot boxes as a revenue source, and many free-to-play games rely almost solely on loot boxes for monetization. Therefore, if loot boxes are banned, many of those companies or at least certain individual games would likely not survive the transition to an alternative monetization model. Like probability disclosures, the ethical game design approach still maintains elements of consumer freedom, and yet by making loot box rewards simpler to understand it should significantly reduce problematic spending by individual players. This would prevent the current ongoing trend towards more complex, and potentially exploitative, forms of loot box and video game monetization (Ballou et al., 2020; Petrovskaya \& Zendle, 2021). Video game companies should be invited to voluntarily adopt and experiment with these ethical game design measures, and those companies that desire to act transparently, socially responsibly, and ethically towards their players will likely do so (as demonstrated by, for example, Blizzard Entertainment's aforementioned duplicate protection measure, which was intended to improve the player experience and likely was also commercially beneficial by providing good PR and increasing sales). However, law or industry self-regulation can also be used to impose these measures as compliance requirements if the rate of voluntary uptake is unsatisfactory, similarly to how this has been done in relation to probability disclosures (Xiao, Henderson, \& Newall, 2021).

It should be noted, however, that the proposals presented herein are theoretical and their efficacy remains to be assessed. Regardless of how and why these measures are implemented, empirical research should be conducted alongside their implementation to assess their effectiveness, perhaps through collaborations between the industry and academia. If the measures are effective at reducing spending among at-risk players, then they should be promoted, and perhaps required by regulation. However, if 
they are ineffective, then they should be promptly abandoned in favour of other possible harm reduction techniques that must be developed. While loot boxes are not the only consumer product that has become more complex and potentially exploitative over time (Bar-Gill, 2012; Heidhues et al., 2017; Sunstein, 2020; Thaler, 2018), the digital nature of loot boxes present unique opportunities to reduce product complexity and therefore potentially reduce harm through ethical design.

\section{Copyright Notice}

The Authors acknowledge that the copyright of all screenshots of video games used in this paper are retained by their respective copyright holders. The Authors use these copyrighted materials for the purposes of research, criticism or review under the fair dealing provisions of copyright law in accordance with Sections 29(1) and 30(1) of the UK Copyright, Designs and Patents Act 1988.

\section{Funding}

L.Y.X. is supported by a $\mathrm{PhD}$ Fellowship funded by the IT University of Copenhagen (IT- Universitetet $\mathrm{i}$ København), which is publicly funded by the Kingdom of Denmark.

\section{Declaration of conflict of interest}

L.Y.X. was employed by LiveMe, a subsidiary of Cheetah Mobile (NYSE:CMCM) as an in-house counsel intern from July to August 2019 in Beijing, People's Republic of China. L.Y.X. was not involved with the monetization of video games by Cheetah Mobile or its subsidiaries. L.Y.X. has accepted conference travel and attendance grants from the Socio-Legal Studies Association (February 2022) and the Current Advances in Gambling Research Conference Organising Committee with support from Gambling Research Exchange Ontario (GREO) (February 2022). L.Y.X. was supported by academic scholarships awarded by The Honourable Society of Lincoln's Inn and The City Law School, City, University of London. P.W.S.N. is a member of the Advisory Board for Safer Gambling - an advisory group of the Gambling Commission in Great Britain, and in 2020 was a special advisor to the House of Lords Select Committee Enquiry on the Social and Economic Impact of the Gambling Industry. In the last five years P.W.S.N. has contributed to research projects funded by the Academic Forum for the Study of Gambling, Clean Up Gambling, GambleAware, Gambling Research Australia, NSW Responsible Gambling Fund, and the Victorian Responsible Gambling Foundation. P.W.S.N. has received travel and accommodation funding from the Spanish Federation of Rehabilitated Gamblers, and received open access fee grant income from Gambling Research Exchange Ontario. 


\section{Availability of data and material}

The data used for the reanalysis of Xiao, Fraser, \& Newall (2021) is available via: https://osf.io/agbf4/.

\section{Author's contributions}

L.Y.X.: Conceptualisation; Data Curation; Formal Analysis; Project Administration; Resources; Software; Visualization; Writing - Original Draft Preparation (lead); Writing - Review \& Editing

P.W.S.N.: Conceptualisation; Supervision; Writing - Original Draft Preparation; Writing - Review \& Editing.

\section{Ethics and informed consent}

Not applicable to a reanalysis of preexisting public data. Ethics approval and informed consent were obtained for the original data collection of Xiao, Fraser, \& Newall (2021).

Note Credit is due to an anonymous reviewer for suggesting this reanalysis. 


\section{References}

Ballou, N., Gbadamosi, C. T. T., \& Zendle, D. (2020). The hidden intricacy of loot box design: A granular description of random monetized reward features. PsyArXiv Preprints. https://doi.org/10.31234/osf.io/xeckb

Bar-Gill, O. (2012). Seduction by contract: Law, economics, and psychology in consumer markets. In Seduction by Contract. Oxford University Press. https://oxford.universitypressscholarship.com/view/10.1093/acprof:oso/9780199663361. 001.0001/acprof-9780199663361

Bar-Gill, O. (2021). Smart disclosure: Promise and perils. Behavioural Public Policy, 5(2), 238251. https://doi.org/10.1017/bpp.2019.24

Batchelor, J. (2020, March 6). Australian Parliamentary committee recommends loot box regulation. GamesIndustry.Biz. https://www.gamesindustry.biz/articles/2020-03-06australian-parliamentary-committee-recommends-loot-box-regulation

BBC. (2019, January 3). Gaming worth more than video and music combined. BBC News. https://www.bbc.com/news/technology-46746593

Belgian Gaming Commission. (2018). Onderzoeksrapport loot boxen [Research Report on Loot Boxes].

https://www.gamingcommission.be/opencms/export/sites/default/jhksweb_nl/documents/ onderzoeksrapport-loot-boxen-final-publicatie.pdf

Brooks, G. A., \& Clark, L. (2019). Associations between loot box use, problematic gaming and gambling, and gambling-related cognitions. Addictive Behaviors, 96, 26-34. https://doi.org/10.1016/j.addbeh.2019.04.009

Cerulli-Harms, A., Münsch, M., Thorun, C., Michaelsen, F., \& Hausemer, P. (2020). Loot boxes in online games and their effect on consumers, in particular young consumers (PE 652.727). Policy Department for Economic, Scientific and Quality of Life Policies (EU). https://www.europarl.europa.eu/RegData/etudes/STUD/2020/652727/IPOL_STU(2020)6 52727_EN.pdf

Chen, N., Elmachtoub, A. N., Hamilton, M. L., \& Lei, X. (2020). Loot box pricing and design. Management Science, 67(8), 4809-4825. https://doi.org/10.1287/mnsc.2020.3748

Close, J., Spicer, S. G., Nicklin, L. L., Uther, M., Lloyd, J., \& Lloyd, H. (2021). Secondary analysis of loot box data: Are high-spending "whales" wealthy gamers or problem gamblers? Addictive Behaviors, 117, 106851. https://doi.org/10.1016/j.addbeh.2021.106851

Dealessandri, M. (2021, April 6). Brazil launches inquiry to ban loot boxes. GamesIndustry.Biz. https://www.gamesindustry.biz/articles/2021-04-06-brazil-launches-inquiry-to-ban-lootboxes

Derrington, S., Star, S., \& Kelly, S. J. (2021). The case for uniform loot box regulation: A new classification typology and reform agenda. Journal of Gambling Issues, 46, 302-332. https://doi.org/10.4309/jgi.2021.46.15

Drummond, A., \& Sauer, J. D. (2018). Video game loot boxes are psychologically akin to gambling. Nature Human Behaviour, 2(8), 530-532. https://doi.org/10.1038/s41562-0180360-1

Drummond, A., Sauer, J. D., Ferguson, C. J., \& Hall, L. C. (2020). The relationship between 
problem gambling, excessive gaming, psychological distress and spending on loot boxes in Aotearoa New Zealand, Australia, and the United States-A cross-national survey. PLOS ONE, 15(3), e0230378. https://doi.org/10.1371/journal.pone.0230378

Drummond, A., Sauer, J. D., \& Hall, L. C. (2019). Loot box limit-setting: A potential policy to protect video game users with gambling problems? Addiction, 114(5), 935-936. https://doi.org/10.1111/add.14583

Electronic Arts. (2019, September 19). Pack Probability in FIFA Ultimate Team. Electronic Arts Inc. https:/www.ea.com/games/fifa/news/fifa-pack-probabilities

Fischhoff, B., \& Bruin, W. B. D. (1999). Fifty-Fifty = 50\%? Journal of Behavioral Decision Making, 12(2), 149-163. https://doi.org/10.1002/(SICI)10990771(199906)12:2<149::AID-BDM314>3.0.CO;2-J

Garcia-Retamero, R., \& Cokely, E. T. (2017). Designing visual aids that promote risk literacy: A systematic review of health research and evidence-based design heuristics. Human Factors, 59(4), 582-627. https://doi.org/10.1177/0018720817690634

Garea, S. S., Drummond, A., Sauer, J. D., Hall, L. C., \& Williams, M. N. (2021). Meta-analysis of the relationship between problem gambling, excessive gaming and loot box spending. International Gambling Studies. https://doi.org/10.1080/14459795.2021.1914705

Gigerenzer, G., \& Hoffrage, U. (1995). How to improve Bayesian reasoning without instruction: Frequency formats. Psychological Review, 102(4), 684-704. https://doi.org/10.1037/0033-295X.102.4.684

Hall, L. C., Drummond, A., Sauer, J. D., \& Ferguson, C. J. (2021). Effects of self-isolation and quarantine on loot box spending and excessive gaming-Results of a natural experiment. PeerJ, 9, e10705. https://doi.org/10.7717/peerj.10705

Heidhues, P., Köszegi, B., \& Murooka, T. (2017). Inferior products and profitable deception. The Review of Economic Studies, 84(1), 323-356. https://doi.org/10.1093/restud/rdw037

Kilkku, V. (2020, March 17). Hearthstone packs are getting total 'duplicate protection', but how much will that actually save you? PC Gamer. https://www.pcgamer.com/uk/hearthstonepacks-are-getting-total-duplicate-protection-but-how-much-will-that-actually-save-you/

King, D. L., \& Delfabbro, P. H. (2019a). Loot box limit-setting is not sufficient on its own to prevent players from overspending: A reply to Drummond, Sauer \& Hall. Addiction, 114(7), 1324-1325. https://doi.org/10.1111/add.14628

King, D. L., \& Delfabbro, P. H. (2019b). Video game monetization (e.g., 'Loot Boxes'): A blueprint for practical social responsibility measures. International Journal of Mental Health and Addiction, 17(1), 166-179. https://doi.org/10.1007/s11469-018-0009-3

Kristiansen, S., \& Severin, M. C. (2019). Loot box engagement and problem gambling among adolescent gamers: Findings from a national survey. Addictive Behaviors, 103, 106254. https://doi.org/10.1016/j.addbeh.2019.106254

Larche, C. J., Chini, K., Lee, C., Dixon, M. J., \& Fernandes, M. (2021). Rare loot box rewards trigger larger arousal and reward responses, and greater urge to open more loot boxes. Journal of Gambling Studies, 37, 141-163. https://doi.org/10.1007/s10899-019-09913-5

Li, W., Mills, D., \& Nower, L. (2019). The relationship of loot box purchases to problem video gaming and problem gambling. Addictive Behaviors, 97, 27-34.

https://doi.org/10.1016/j.addbeh.2019.05.016

Livingstone, C., Rintoul, A., Lacy-Vawdon, C. de, Borland, R., Dietze, P., Jenkinson, R., 
Livingston, M., Room, R., Smith, B., Stoove, M., Winter, R., \& Hill, P. (2019). Identifying effective policy interventions to prevent gambling-related harm. Victorian Responsible Gambling Foundation. https://responsiblegambling.vic.gov.au/documents/640/Livingstone-identifying-effectivepolicy-interventions-June-2019.pdf

Loewenstein, G., Sunstein, C. R., \& Golman, R. (2014). Disclosure: Psychology changes everything. Annual Review of Economics, 6(1), 391-419. https://doi.org/10.1146/annurev-economics-080213-041341

Macey, J., \& Hamari, J. (2019). eSports, skins and loot boxes: Participants, practices and problematic behaviour associated with emergent forms of gambling. New Media \& Society, 21(1), 20-41. https://doi.org/10.1177/1461444818786216

McCaffrey, M. (2019). The macro problem of microtransactions: The self-regulatory challenges of video game loot boxes. Business Horizons, 62(4), 483-495. https://doi.org/10.1016/j.bushor.2019.03.001

Newall, P. W. S., Walasek, L., Hassanniakalager, A., Russell, A. M. T., Ludvig, E. A., \& Browne, M. (2020). Statistical risk warnings in gambling. Behavioural Public Policy. https://doi.org/10.1017/bpp.2020.59

Nicklin, L. L., Spicer, S. G., Close, J., Parke, J., Smith, O., Raymen, T., Lloyd, H., \& Lloyd, J. (2021). "It's the attraction of winning that draws you in" - a qualitative investigation of reasons and facilitators for videogame loot box engagement in UK gamers. Journal of Clinical Medicine, 10(10), 2103. https://doi.org/10.3390/jcm10102103

Nielsen, R. K. L., \& Grabarczyk, P. (2019). Are loot boxes gambling? Random reward mechanisms in video games. Transactions of the Digital Games Research Association, 4(3), 171-207. https://doi.org/10.26503/todigra.v4i3.104

Nintendo. (2019, May 21). Belangrijke informatie voor gebruikers in België [Important Information for Users in Belgium]. Nintendo Belgium. https://www.nintendo.be/nl/Nieuws/2019/mei/Belangrijke-informatie-voor-gebruikers-inBelgie-1561911.html

O’Boyle, D. (2021, February 19). Spain's DGOJ launches consultation on loot box ban. IGaming Business. https://igamingbusiness.com/spains-dgoj-launches-consultation-onloot-box-ban/

Page, L. (2021). Disclosure for real humans. Behavioural Public Policy, 5(2), 225-237. https://doi.org/10.1017/bpp.2019.23

Persson, P. (2018). Attention manipulation and information overload. Behavioural Public Policy, 2(1), 78-106. https://doi.org/10.1017/bpp.2017.10

Petrovskaya, E., \& Zendle, D. (2021). Predatory monetisation? A categorisation of unfair, misleading and aggressive monetisation techniques in digital games from the player perspective. Journal of Business Ethics. https://doi.org/10.1007/s10551-021-04970-6

Rockloff, M., Russell, A. M. T., Greer, N., Lole, L., Hing, N., \& Browne, M. (2021). Young people who purchase loot boxes are more likely to have gambling problems: An online survey of adolescents and young adults living in NSW Australia. Journal of Behavioral Addictions, 10(1), 35-41. https://doi.org/10.1556/2006.2021.00007

Sunstein, C. R. (2020). Sludge audits. Behavioural Public Policy. https://doi.org/10.1017/bpp.2019.32

Thaler, R. H. (2018). Nudge, not sludge. Science, 361(6401), 431-431. https://doi.org/10.1126/science.aau9241 
Todd, P. M., \& Gigerenzer, G. (2012). Ecological rationality: Intelligence in the world. In Ecological Rationality. Oxford University Press. https://doi.org/10.1093/acprof:oso/9780195315448.001.0001

Tversky, A., \& Kahneman, D. (1974). Judgment under uncertainty: Heuristics and biases. Science, 185(4157), 1124-1131. https://doi.org/10.1126/science.185.4157.1124 UK Gambling Commission. (2017). Virtual Currencies, eSports and Social GamingPosition Paper. https://web.archive.org/web/20210111075348/http://www.gamblingcommission.gov.uk/P DF/Virtual-currencies-eSports-and-social-casino-gaming.pdf

von Meduna, M., Steinmetz, F., Ante, L., Reynolds, J., \& Fiedler, I. (2020). Loot boxes are gambling-like elements in video games with harmful potential: Results from a large-scale population survey. Technology in Society, 63, 101395. https://doi.org/10.1016/j.techsoc.2020.101395

Walker, A. C., Stange, M., Dixon, M. J., Koehler, D. J., \& Fugelsang, J. A. (2019). Graphical depiction of statistical information improves gambling-related judgments. Journal of Gambling Studies, 35(3), 945-968. https://doi.org/10.1007/s10899-019-09860-1

Wardle, H., \& Zendle, D. (2021). Loot boxes, gambling, and problem gambling among young people: Results from a cross-sectional online survey. Cyberpsychology, Behavior, and Social Networking, 24(4), 267-274. https://doi.org/10.1089/cyber.2020.0299

Weiss-Cohen, L., Konstantinidis, E., Speekenbrink, M., \& Harvey, N. (2018). Task complexity moderates the influence of descriptions in decisions from experience. Cognition, 170, 209-227. https://doi.org/10.1016/j.cognition.2017.10.005

Whitson, J., \& French, M. (2021). Productive play: The shift from responsible consumption to responsible production. Journal of Consumer Culture, 21(1), 14-33. https://doi.org/10.1177/1469540521993922

Xiao, L. Y. (2021a). Conceptualising the loot box transaction as a gamble between the purchasing player and the video game company. International Journal of Mental Health and Addiction, 19(6), 2355-2357. https://doi.org/10.1007/s11469-020-00328-7

Xiao, L. Y. (2021b). Regulating loot boxes as gambling? Towards a combined legal and selfregulatory consumer protection approach. Interactive Entertainment Law Review, 4(1), 27-47. https://doi.org/10.4337/ielr.2021.01.02

Xiao, L. Y. (2022). Which implementations of loot boxes constitute gambling? A UK legal perspective on the potential harms of random reward mechanisms. International Journal of Mental Health and Addiction, 20(1), 437-454. https://doi.org/10.1007/s11469-02000372-3

Xiao, L. Y., Fraser, T. C., \& Newall, P. W. S. (2021). Opening Pandora's loot box: Novel links with gambling, and player opinions on probability disclosures and pity-timers in China. PsyArXiv Preprints. https://doi.org/10.31234/osf.io/837dv

Xiao, L. Y., \& Henderson, L. L. (2019). Towards an ethical game design solution to loot boxes: A commentary on King and Delfabbro. International Journal of Mental Health and Addiction, 19, 177-192. https://doi.org/10.1007/s11469-019-00164-4

Xiao, L. Y., Henderson, L. L., \& Newall, P. (2021). What are the odds? Lower compliance with Western loot box probability disclosure industry self-regulation than Chinese legal regulation. OSF Preprints. https://doi.org/10.31219/osf.io/g5wd9

Xiao, L. Y., Henderson, L. L., Nielsen, R. K. L., Grabarczyk, P., \& Newall, P. W. S. (2021). 
Loot boxes, gambling-like mechanics in video games. In N. Lee (Ed.), Encyclopedia of Computer Graphics and Games. Springer.

Xiao, L. Y., Henderson, L. L., Yang, Y., \& Newall, P. W. S. (2021). Gaming the system: Suboptimal compliance with loot box probability disclosure regulations in China. Behavioural Public Policy. https://doi.org/10.1017/bpp.2021.23

Zendle, D. (2019a). Gambling-like video game practices: A cross-sectional study of links with problem gambling and disordered gaming. PsyArXiv Preprints. https://doi.org/10.31234/osf.io/fh3vx

Zendle, D. (2019b). Problem gamblers spend less money when loot boxes are removed from a game: A before and after study of Heroes of the Storm. PeerJ, 7, e7700. https://doi.org/10.7717/peerj.7700

Zendle, D., \& Cairns, P. (2018). Video game loot boxes are linked to problem gambling: Results of a large-scale survey. PLOS ONE, 13(11), e0206767. https://doi.org/10.1371/journal.pone.0206767

Zendle, D., \& Cairns, P. (2019). Loot boxes are again linked to problem gambling: Results of a replication study. PLOS ONE, 14(3), e0213194. https://doi.org/10.1371/journal.pone.0213194

Zendle, D., Cairns, P., Barnett, H., \& McCall, C. (2019). Paying for loot boxes is linked to problem gambling, regardless of specific features like cash-out and pay-to-win. Computers in Human Behavior, 102, 181-191. https://doi.org/10.1016/j.chb.2019.07.003

Zendle, D., Meyer, R., Cairns, P., Waters, S., \& Ballou, N. (2020). The prevalence of loot boxes in mobile and desktop games. Addiction, 115(9), 1768-1772. https://doi.org/10.1111/add.14973

Zendle, D., Meyer, R., \& Over, H. (2019). Adolescents and loot boxes: Links with problem gambling and motivations for purchase. Royal Society Open Science, 6, 190049. https://doi.org/10.1098/rsos.190049

Zendle, D., Petrovskaya, E., \& Wardle, H. (2020). How do loot boxes make money? An analysis of a very large dataset of real Chinese CSGO loot box openings. https://doi.org/10.31234/osf.io/5k2sy 


\section{Figure 1}

A screenshot of the loot box purchase screen and probability disclosure of Slots (Golden HoYeah) - Casino Slots

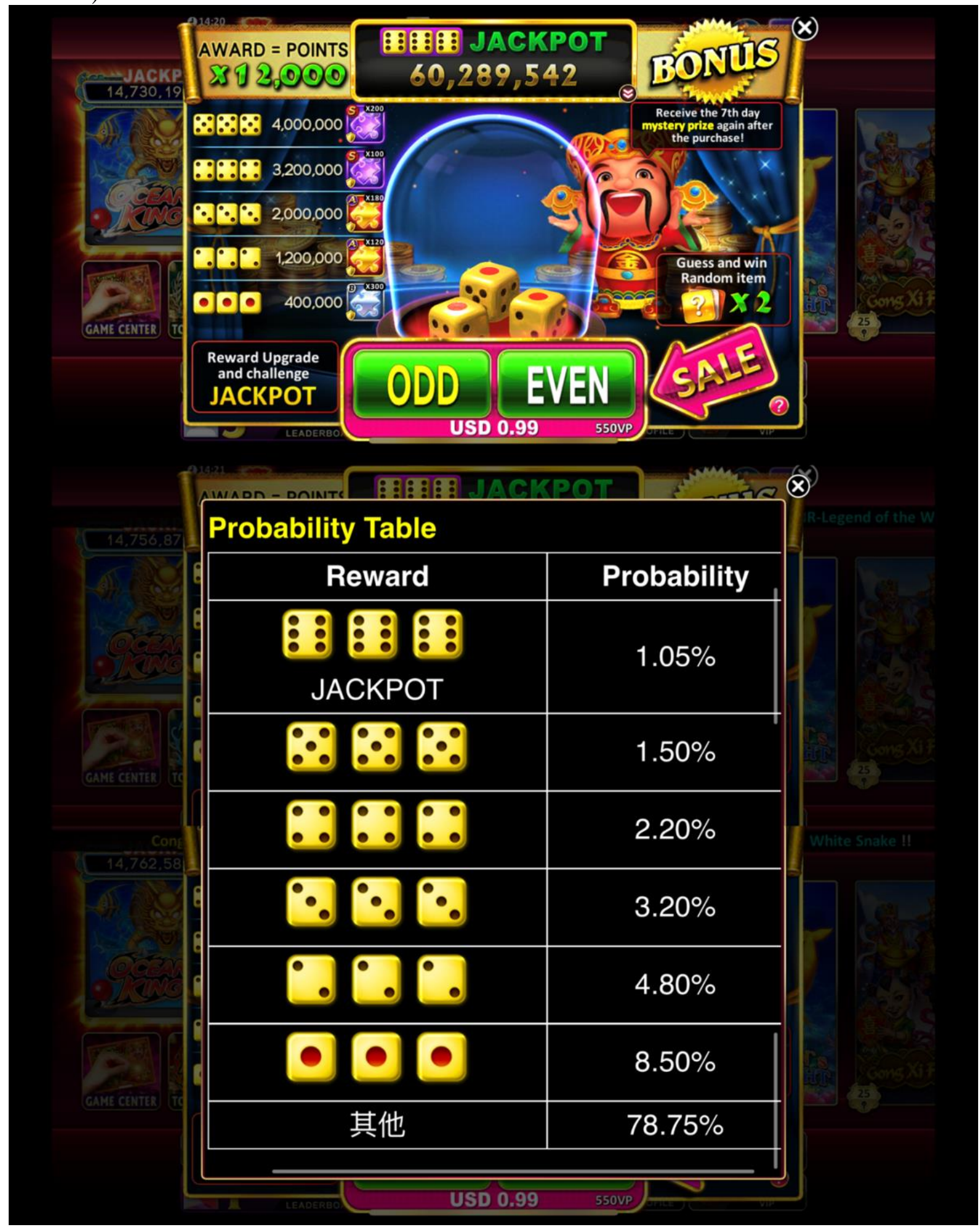

Note: 其他 is Simplified Chinese for “Other.” (C2020 International Games System. 


\section{Figure 2}

The probability disclosure for Mario Kart Tour

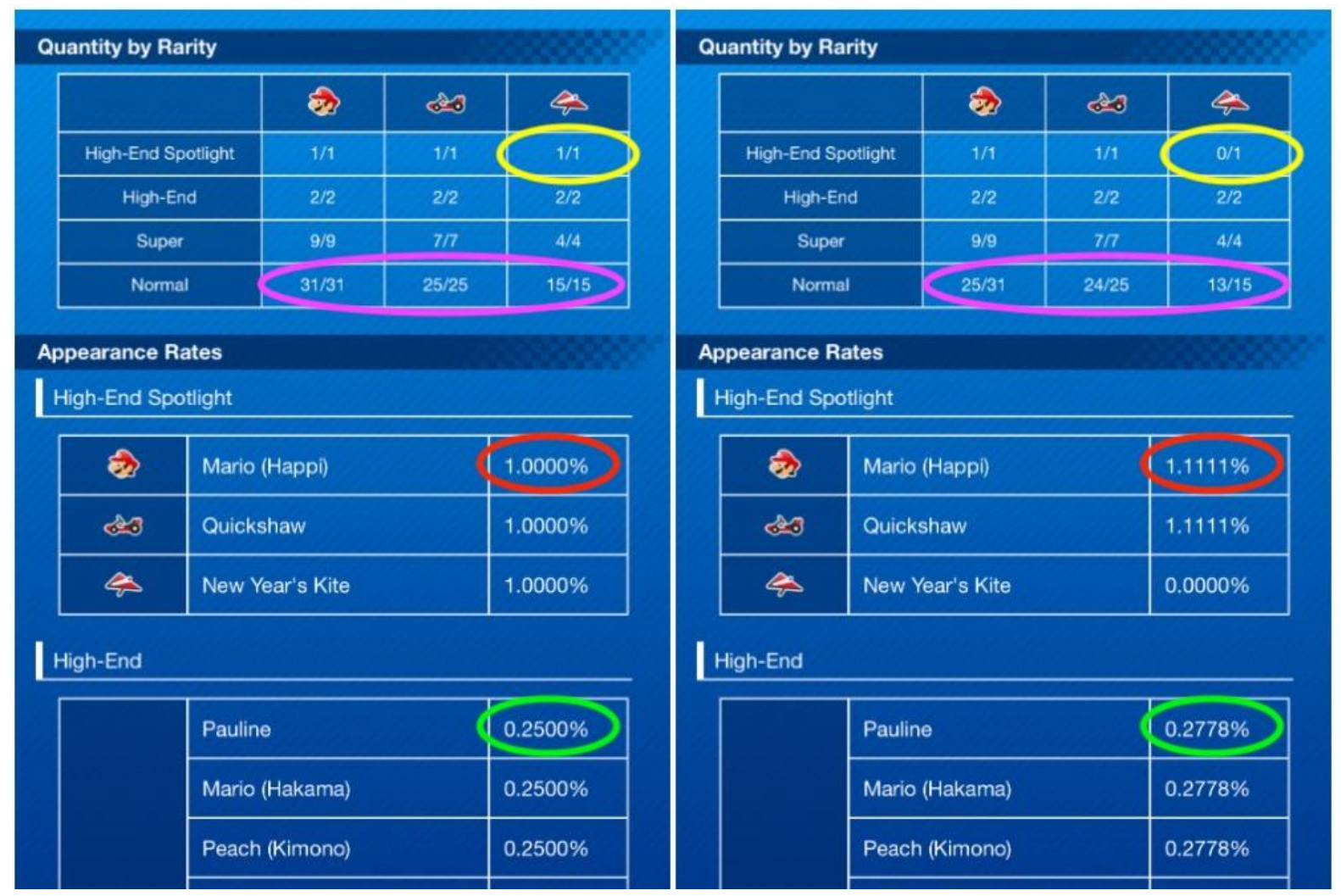

Notes. Probabilities are updated live as the player purchases more loot boxes, as demonstrated by the corresponding values in the differently colored circles. This loot box implementation is also partially exhaustible: it contains 100 rewards; of these 100 rewards, three of them are guaranteed to be "High-End Spotlight," meaning that if the player buys all 100 loot boxes, then they are guaranteed to eventually obtain all three "High-End Spotlight" rewards. The player may also be "luckier" and obtain these before having purchased all 100 loot boxes. (C2019-2020 Nintendo. 